
Russ.)

Meillassoux, Q. (2015) Posle konechnosti. Ekaterinburg, Moscow, Kabinetnyi uchenyi. 194 p. (In

Meillassoux, Q. (2017) Iteratsiia, reiteratsiia, povtorenie. Spekuliativnyi analiz znaka, lishennogo smysla. Translit, no. 19, pp. 77-85. (In Russ.)

Morozov, A. (2019) Navigatsiia po akseleratsionizmu: ot nekapitalizma k postkapitalizmu cherez platformy. Galactica Media: Journal of Media Studies, vol. 1, no. 2, pp. 226-242. DOI: 10.24411/ 2658-7734-2019-10020. (In Russ.)

Brassier, R. (2007) Nibil Unbound: Enlightenment and Extinction. New York, Palgrave Macmillan. 275 p.

Kolozova, K. (2009) Thinking the Political by Way of "Radical Concepts". International Journal of Žižek Studies, vol. 3, no. 1 [online] Available at: http://zizekstudies.org/index.php/IJZS/article/ view/135/135 (accessed: 17.03.2020).

Laruelle, F. (2015) General Theory of Victims. Malden, MA, Polity Press. 184 p.

Meillassoux, Q. (2011) Excerpts from L'Inexistence divine. In: Harman, G. Quentin Meillassoux: Philosopby in the Making. Edinburgh, Edinburgh University Press. 240 p. Pp. 175-218.

Srnicek, N. (2010) François Laruelle, the One and the Non-Philosophical Tradition. King's College London [online] Available at: http://kclpure.kcl.ac.uk/portal/en/publications/francoislaruelle-the-one-and-the-nonphilosophical-tradition(edf30549-9f4e-4645-a176-a0e4e19b6d9d).html (accessed: 17.03.2020).

Submission date: 18.03 .2020$.

Морозов Артем Владимирович - младший научный сотрудник сектора социальной философии Института философии РАН. Адрес: 109240, Россия, г. Москва, ул. Гончарная, А. 12, стр. 1. Тел.: +7 (495) 697-98-93. Эл. аapec: morozov.socphil@yandex.ru

Morozov Artem Vladimirovich, Junior Research Fellow, Sector of Social Philosophy, RAS Institute of Philosophy. Postal address: 12, Bldg. 1, Goncharnaya St., Moscow, Russian Federation, 109240. Tel.: +7 (495) 697-98-93. E-mail: morozov.socphil@yandex.ru

DOI: $10.17805 / z p u .2020 .2 .21$

\title{
Социологическая концептуализация электронных денег: сложности и перспективы
}

\author{
E. C. МАКАРОВ
}

РОССИЙСКИЙ ЭКОНОМИЧЕСКИЙ УНИВЕРСИТЕТ ИМЕНИ Г. В. ПЛЕХАНОВА

В статье представлена концептуализация электронных денег в рамках различных социологических оптик. Электронные деньги рассматриваются как множественный феномен, встроенный в социальную жизнь как на уровне смыслов, так и на повседневном уровне.

На основе анализа феномена электронных денег через призму двух концептуальных оптик - теории множественных денег В. Зелизер и материальной социологии повседневности В. Вахштайна - делаются выводы о возможностях совместимости двух концепций и некоторых их принципиальных различиях.

Ключевые слова: электронные деньги; социология денег; экономическая социология; множественные деньги; социология повседневности 
ВВЕАЕНИЕ

Аньги в качестве объекта социологического исследования рассматривались в раФботах классиков социологии, например К. Маркса, М. Вебера, Г. Зиммеля. Но начиная примерно с 1985 г. особую популярность анализ денег приобрел в контексте так называемой новой экономической социологии (Радаев, 2008: 117).

В рамках данного направления исследователи распространили социологическую оптику на объекты, которые привычно мыслились экономистами: помимо денег это были также рынки, организации, конкуренция и т. А. Одной из основных идей стала концепция укорененности экономического действия в социальной структуре (Грановеттер, 2014), рассматриваемая в более широком контексте критики модели «человека экономического» (bomo economicus) (Бурдье, 2019). Включение социального измерения не обошло стороной и анализ денег, что предполагает наличие у них социального и символического значений. При таком подходе деньги рассматриваются не как «совершенно однородный, бесконечно делимый, ликвидный объект, лишенный всякого качества» (Зелизер, 2004: 43), а, напротив, как окрашенные социальными взаимодействиями и смысловыми значениями множественные социальные посредники. И в России, и за рубежом становятся популярными различные исследования финансового поведения именно в такой, социологической, логике (Маркин, 2015; Халина, 2013; Зелизер, 2004; Smithin, 2000; Ingham, 2004).

Однако реальность стремительно меняется, и сегодня мы уже вовсю используем не только банкноты и монеты, но и электронные средства платежа: пластиковые карты и мобильные телефоны активно встраиваются в нашу жизнь. Изменение реальности стимулирует и «обновление» концептуальных оптик, в связи с чем в современной социологической теории набирают популярность акторно-сетевая теория, социология вещей, социология техники (Вахштайн, 2017; Матур, 2020), внимание исследователей все чаще стали привлекать электронные деньги (Маркин, 2015; Халина, 2013). Но не совсем ясно, каким образом социологические теории денег (и не только непосредственно денег) могут описывать появление электронных способов оплаты в нашей жизни. Как электронные деньги встраиваются в нашу повседневную жизнь, наделяем ли мы их особыми смыслами и «окрашиваются» ли они социальными взаимодействиями?

На обсуждение данных вопросов и направлена данная работа, а ее цель - представить концептуализацию электронных средств платежа в рамках современной социологической теории.

Необходимо отметить, что в данной статье не будут рассматриваться те социологические теории, в которых деньги представлены как мера всеобщего эквивалента, превращающая качество в количество, рационализирующая социальные отношения и стремящаяся сделать из них однородную «массу» (обзор данных теорий см.: Зелизер, 2004: 31-44; Аникаева, 2008: 115-119). Такая логика мышления близка к «ортодоксальной» экономической теории (Ingham, 2000: 17). В этой работе будут рассматриваться концепции, с помощью которых можно описать множественность социальных значений денег и их форм, а также будет представлен анализ электронных денег с точки зрения повседневной жизни (с помощью языка социологии повседневности).

\section{МНОЖЕСТВЕННЫЕ ЭАЕКТРОННЫЕ АЕНЬГИ}

Аля начала обратимся к концепции «множественных денег» американского социолога В. Зелизер. Термин «множественность» сам по себе уже противопоставляется однородности. Зелизер видит в деньгах множественный, а не однородный феномен, 
стандартизирующий социальные отношения. Это означает не только то, что деньги множественны в своей физической форме (речь идет, например, о различных физических средствах обмена в США во второй половине XIX в., унифицировать которые пыталось американское правительство (Зелилер, 2004: 44-52)), но и то, что люди действуют исходя из множества смыслов, которые они придают деньгам. К примеру, предложить взятку преподавателю - совсем не то же самое, что сделать ему подарок, поэтому даже сделанный от чистой души подарок в виде пятитысячной купюры будет, скорее всего, распознан как предложение взятки (о маркировке подарков см.: Зелизер, 2004: 123-131). В различных социальных контекстах и формах взаимодействия наше финансовое поведение будет различным. К тому же деньги, полученные из разных источников, расходуются совершенно по-разному. Например, Зелизер пишет: «Получив по решению суда материальную компенсацию за смерть ребенка... истцы из среднего класса скорее всего поступят с полученной суммой ритуальным образом пожертвуют на благотворительные цели, передадут организациям, занимающимися охраной порядка, или на обучение детей из бедных семей» (Зелизер, 2004: 65). Вокруг «целевого распределения денег» (термин «целевое распределение» Зелизер заимствует у Карла Поланьи (там же: 56)) существуют ценностные системы и социальные нормы, регулирующие данное распределение. Именно в этом и проявляется множественность денег. Аругой вопрос, который ставит Зелизер: каким образом люди разделяют деньги для различных целей, как они маркируют деньги в условиях их физической однородности? Ее ответ: «Существует множество различных способов: например ограничение использования денег, контроль за их распределением, выделение конкретного места для хранения определенных денег...» (там же: 66).

В связи с этим позволим себе сделать несколько замечаний. Во-первых, таким образом Зелизер не разделяет функционирование денег в обществах с рыночной и нерыночной экономиками (или, как выразился бы П. Бурдье, «символическими экономиками» и «экономическими экономиками» (Бурдье, 2019)). Ссылаясь на работы британского антрополога М. Ауглас, Зелизер отмечает, что, проводя границу между распределением денег в докапиталистических и капиталистических обществах, нельзя дать «удовлетворительного объяснения денег» (Зелизер, 2004: 58). Следовательно, необходимо дать такое объяснение денег, исходя из их множественности, которое распространялось бы и на рыночные, и на нерыночные типы обществ. Но сама Зелизер в своей работе ограничивается теми сферами, в которых деньги не играют в первую очередь роль рыночного обмена: она исследует «механизмы контроля и их целевого распределения тогда и в тех обстоятельствах, когда они касаются щекотливых или сложных форм социального взаимодействия» (там же: 61), а именно в семейных отношениях, в установлении или поддержании неравенства, в маркировке статусных различий, в социальной помощи беднякам, в благотворительности и т. А. В таком случае не затрагивается вопрос о социальном значении денег в собственно экономической сфере. Аанный вопрос представляет отдельный исследовательский интерес (о символическом измерении в экономическом поле см.: Бурдье, 2019). Аеньги, согласно концепции Зелизер, в различных социальных отношениях могут наделяться различными значениями, в соответствии с которыми люди будут осуществлять их целевое распределение. Но в первую очередь речь идет о наиболее острых социальных вопросах (возможно, пограничных или конфликтных ситуациях), а не о строго экономическом обмене.

Зелизер фактически видит за деньгами социальные отношения, которые трансформируют значение денег и сами трансформируются в этом контексте. К примеру, 
вопрос относительно того, кто должен управлять семейным бюджетом: муж или жена? Если им управляет муж, то каким образом он маркирует деньги на жену: как деньги «на булавки», как оплату за домашнюю работу (в тот исторический период, который исследует Зелизер (1870-1920), американки в большинстве своем выполняли работу по дому, а не осуществляли трудовую деятельность наравне с мужчинами) или же существует общий семейный бюджет, одинаково доступный партнерам и контролируемый ими? Вокруг подобных вопросов нередко возникают дискуссии и конфликты, приводящие к изменению социального значения денег, а вместе с тем и к трансформации самих этих отношений. Помимо прочего стоит отметить, что Зелизер, хотя и говорит о практиках обращения с деньгами, однако, применяя ее оптику, вряд ли можно увидеть то, как мы используем их в повседневной жизни (на что может пролить свет социология повседневности). Скорее, теория множественных денег поможет в поиске смыслов и значений, которые скрываются за социальными отношениями и практиками, а также тех ценностных систем и социальных норм, которые регулируют целевое распределение денег (нередко влияние оказывают такие институты, как государство, семья, религия и т. А.).

Что можно увидеть сквозь призму множественных денег в контексте распространения электронных денег? Сразу отметим, что «электронные деньги» в данной работе рассматриваются в широком контексте как «не-наличные и не-бумажные платежные инструменты: пластиковые карты и любые денежные переводы с использованием различных электронных каналов (банкоматы, роs-терминалы, факс, телефон или Интернет)» (Халина, 2013: 124). В таком случае под «электронными деньгами» понимаются различные формы электронных платежей, в том числе те средства, которые хранятся на счетах, привязанных к пластиковым картам. Исходя из концепции Зелизер, следует спросить, проводят ли люди границу между электронными и неэлектронными 1 (наличными) деньгами, и если да, то в каких случаях? Осуществляют ли они целевое распределение электронных денег или же для них не важно, какими формами денежных средств они будут пользоваться? Влияет ли то, что люди получили деньги электронным способом, на их дальнейшее целевое распределение? Какие нормативные и ценностные механизмы регулируют их финансовое поведение касательно электронных денег?

Аействительно, концепция множественных денег способна описывать те границы, которые проводят люди относительно электронных и неэлектронных денег. Как показано в одном из исследований, проблема семейных финансов приобретает новый характер в контексте распространения әлектронных денег: один из респондентов скорее согласится дать жене какое-то количество денег наличными, нежели доверить свою кредитную карточку (Халина, 2013: 127). Как показывает В. Зелизер в своей работе, семейный бюджет всегда был одним из тех острых вопросов, в которых деньги играли важнейшее значение и наполнялись смыслами. А перевод семейного бюджета в электронный формат может порождать новые вопросы и трансформировать семейные отношения. В современном мире женщины куда более вовлечены в трудовую деятельность, чем в начале XX в. (тот период, который исследует Зелизер). И как в условии того, что большинство зарплат приходят на электронный счет, супругам отследить их размер и получение (если перед ними стоит такая задача)? Выходит, что электронные деньги открывают новые способы скрыть свой доход в семье. Аанные вопросы представляют интерес с точки зрения эмпирического исследования, но это также означает, что с помощью концепции множественных денег возмож- 
но провести различие между электронными и неэлектронными деньгами (Маркин, 2015: 128-129).

Но как обстоят дела в собственно экономической сфере? Концепция Зелизер, как отмечалось выше, хорошо описывает проблематику электронных денег в тех сферах, которые наиболее полно окрашены социальным измерением и смыслами. Можно предположить, что электронные деньги влияют на функционирование теневой экономики. Перевод бизнеса в безналичный расчет - хороший способ сделать все «прозрачным», и, возможно, это будет в интересах государства. Если со стороны государства действительно принимаются меры по такому переводу, то какие стратегии могут быть использованы бизнесом, чтобы уйти от этого? Аействительно ли в такой ситуации электронные и неэлектронные деньги будут наделяться разными смыслами и будет ли проводиться граница для осуществления целевого распределения денег? Это предмет прошлых, настоящих или будущих эмпирических исследований.

Таким образом, оптика множественных денег позволяет описать проблематику электронных денег, особенно тогда, когда речь идет о внеэкономической сфере (что было хорошо продемонстрировано здесь: Маркин, 2015; Халина, 2013). Однако относительно экономического поля на данный момент сложно сказать, осуществляется ли, например, целевое распределение электронных денег в бизнесе, и если да, то каким образом. К тому же, как отмечалось выше, концепция Зелизер, на наш взгляд, хорошо подходит для выявления смыслов и социальных значений денег, в то время как использование электронных средств в повседневности сложно схватывается. Аалее обратимся к тем теоретическим ресурсам, которые предоставляет нам язык социологии повседневности для концептуализации электронных денег.

\section{ЭАЕКТРОННЫЕ АЕНЬГИ В ПОВСЕАНЕВНОЙ ЖИЗНИ}

Социология повседневности - широкая область социологической теории, берущая свое начало от феноменологической социологии А. Шюца. В ней существует множество концепций со своими особенностями, такие как теория практик, фрейм-анализ, этнометодология и т. А. Но в последнее время в связи с популярностью акторносетевой теории и требованием вернуть материальные объекты в социологический анализ сама социология повседневности подвергается «пересборке» (Вахштайн, 2017). В данной части работы попробуем показать, каким образом концептуальная рамка социологии повседневности поможет в исследовании электронных денег.

Аля нас стала нормой оплата покупки в магазине банковской картой, проезд в автобусе с помощью электронной оплаты через телефон или магнитную карту с предоплаченным числом поездок; мы можем заказать товар из любой точки мира в один клик, расплатившись с помощью электронного перевода со своего банковского счета. Аа, по сравнению с эпохой бумажных денег наша жизнь кажется гораздо удобнее. Но есть ли какие-то кардинальные изменения с точки зрения нашей повседневной жизни? Бумажные деньги раньше тоже конституировали повседневные взаимодействия, выполняя как роль «установления событийной связи», так и «сигнализации», или маркировки, повседневных событий. Существуют ли качественные отличия электронных денег от бумажных?

Аля начала кратко опишем «пересобранную» теорию повседневности В. Вахштайна и рассмотренные им причины ее переосмысления.

Речь идет о том, что материальные объекты не просто встраиваются в нашу жизнь (они всегда были в нее встроены), а выполняют роль субъекта социального дейст- 
вия - по крайней мере так они начинают трактоваться. В связи с чем встает вопрос, а можно ли называть действие технического объекта социальным, если социальное действие есть действие человека, которое «по своему подразумеваемому действующим или действующими смыслу соотнесено с поведением других людей и ориентируется на него в своем протекании» (Вебер, 2016: 68). Ао недавнего времени материальные объекты не могли мыслиться как субъекты социального действия, однако новые технологии (машины на автопилоте, летающие дроны и т. А.) поставили под вопрос данное положение социальной теории (Вахштайн, 2017: 3). Это с одной стороны. С другой стороны, в самой социальной теории проблематизируется традиционное понимание «социального» как главной категории социологии (Цатур, 2020). «Беда пришла откуда не ждали»: в области социологии науки, в которой примерно до 1980-х гг. господствовал социальный конструктивизм, объясняющий научную деятельность в духе конструирования такого-то научного факта в социальных практиках такого-то научного сообщества, появляется ряд исследователей (Б. Аатур, М. Каллон, Аж. Ао), утверждающих, что «не «социальное» объясняет конструирование знаний, а создание «гетерогенных сетей», которые связывают воедино различные элементы, в том числе людей и «не-человеков» (Жэнгра, 2017: 99). Не вдаваясь в подробности, можно сказать, что одним из результатов такого вторжения в язык социальной науки является то, что нематериальным объектам стало уделяться внимание наравне с людьми, к тому же за объектами теперь признается способность действовать.

Итак, одна из проблем, которая сегодня решается в социологии повседневности, это то, каким образом материальные объекты конституируют и трансформируют нашу повседневную жизнь (Вахштайн, 2017). И все-таки, что же существенно изменилось с точки зрения электронных денег в повседневной жизни?

Первое: по сравнению с бумажными деньгами их электронные аналоги не просто маркируют ситуацию и конституируют фреймы, но еще и обладают перформативной силой. «Материальные объекты конституируют, упорядочивают и поддерживают социальное взаимодействие. Но они же обладают способностью к его трансформации. Поддержание и трансформация порядка интеракции - два функциональных комплекса вещей, инкорпорированных в социальное взаимодействие» (там же: 30 ).

Как именно электронные деньги трансформируют порядок? Наш телефон смартфон - «совершает» огромное количество действий за нас: сегодня вполне обыденно, что с нашего банковского счета каждый месяц будет списываться оплата за Интернет, за подписку для просмотра Английской футбольной премьер-лиги или за прослушивание музыки на нашей любимой мультимедийной платформе. Аля этого достаточно настроить соответствующие опции в телефоне, к которому «привязан» банковский счет. Телефон в одну секунду может поменять цифру нашего счета в банке. Мы делегируем огромное количество таких операций нашим устройствам, тем самым упрощая себе жизнь, и даже не задумываемся о том, что техника фактически сама «управляет» нашими денежными средствами. Тут может быть поставлен отдельный вопрос относительно доверия: насколько мы доверяем нашим гаджетам осуществлять сделки за нас? Британский социолог Аж. Ингэм считает (и в этом плане строго расходится во мнениях с экономистами), что денежный обмен нужно представлять не просто как бартер, в котором деньги выполняют роль «невидимой вуали». Обмен в капиталистическом обществе даже не двухсторонний. В него неизбежно включена третья сторона: "Аеньги неизбежно встроены в социальные отношения между экономическими агентами, а также между ними и “авторитетом” денег... Капи- 
талистическая кредитная денежная система качественно отличается от других денежных форм, так как покоится на обещании в возврате денег» (Ingham, 2000: 19; перевод наш. - E. M.).

Получается, что если наличие доверия к деньгам, которое покоится на их «авторитете», и так является неотъемлемой чертой денежной системы, то феномен электронных денег должен поддерживаться доверием к перформативности гаджетов, изменяющих цифру банковского счета. Аелегирование определенных финансовых действий нашим гаджетам поднимает совершенно новые вопросы: до какой степени мы можем доверить нашему телефону «расплачиваться» самостоятельно? Как было сказано выше, некоторые мужья не доверяют личные банковские карты, электронные счета своим женам, в то время как в полное распоряжение предоставляют их своим электронным устройствам. Итак, фиксируем, первая характеристика - перформативность.

Вторая характеристика связана с вопросом «где локализовано действие?». Предположим, вы совершаете покупку товара, расположенного, например, на другом конце Москвы, или на другом конце России, или вообще в другой стране. Производите оплату товара вы у себя дома, тогда как физически он расположен в совершенно другом месте. Ао эпохи цифровых денег такое было невозможно: вы меняли деньги на товар в одном акте обмена, находясь при этом в одном фрейме, или, выражаясь словами Вахштайна, в жесткой «сцепке»с деньгами и товаром, при этом физически ощущая как товар, который вы приобретаете, так и ту сумму, с которой вам приходится расстаться. Что происходит теперь, когда вы находитесь дома, товар - в другом месте, а деньги - вообще на виртуальном счете? Это состояние «расцепления», причем в момент покупки электронные деньги являются тем, что позволит ваше взаимодействие с товаром превратить в «сцепленное» состояние. Электронные деньги позволяют вам осуществлять покупку, не будучи «сцепленными» с товаром. Наоборот, они «переводят» из состояния расцепления (вы находитесь в одном месте, товар - в другом) в состояние «сцепки», точнее, позволяют совершить покупку вне сцепленного формата взаимодействия между вами, продавцом, товаром и деньгами. (На языке Аатура нужно идти дальше и сказать, что деньги в электронном виде являются посредником, хотя, конечно, с точки зрения акторно-сетевой теории электронные деньги - нематериальный актант, встроенный в сеть акторов и производящий в ней различие, о чем речь будет идти далее; подробнее об этом см.: Аатур, 2020). При этом самих денег физически вы не видите и не чувствуете. Более того, если представить фрейм передачи вам товара доставщиком при совершенной оплате заранее через электронный счет, в нем физически не будут присутствовать сами бумажные средства (маркеры того, что в данный момент осуществляется экономическая сделка). Тогда каким образом маркируется по смыслу ваше взаимодействие с доставщиком? Оно маркируется наличием товара и информацией о нем (или, кстати говоря, услуги, но это еще сильнее усложняет дело, так как теперь нематериальных сущности две - электронные деньги и услуга), которые вы получаете как «акт обмена», а не наличием в нем денег, которые маркируют «акт покупки». «Акт покупки» был произведен вами заранее, и именно данный акт маркируют деньги, причем как электронные, так и неэлектронные. Электронные деньги делают возможным расцепление двух этих актов во времени, но при этом осуществляют сцепку в пространстве. (В этом плане электронные деньги оказывают огромное влияние на увеличение уровня мобильности; о связи мобильностей и денег см.: Попов, 2011). Электронные деньги позволяют сцеплять удаленные в пространстве объекты. 
Но идет ли здесь речь о самих электронных деньгах? Или же показанные выше явления делают возможными не сами электронные деньги, а, скорее, гаджеты, через которые мы получаем доступ к виртуальному электронному счету?

Теперь можно приступить к рассуждениям, которые смогут привести к нескольким важным концептуальным выводам относительно проблематики электронных денег как объекта социологического анализа с точки зрения разных уровней. Отличие электронных и неэлектронных денег через призму того, что В. Вахштайн назвал «модусами существования» вещей в повседневной жизни, привело к тому, что электронные деньги на первый взгляд могут играть перформативную роль (делегирование нами устройствам некоторых функциональных возможностей манипуляции с нашими электронными счетами) и роль сцепки/расцепления, расцепляя «акт покупки» и «акт оплаты» во времени, при этом сцепляя вас и товар. Однако то, что это становится возможным, заслуга не просто появления феномена электронных денег, а в первую очередь электронных технологий. Электронные деньги по сравнению с бумажными не ощущаются нами физически: сами деньги перестали быть объектом, вещью, конституирующей повседневные взаимодействия. Электронные деньги, в отличие от своих бумажных аналогов, имеют символическое значение в виде неких цифр, при этом не обязательно воплощаются в материальной форме. И это очень важно с точки зрения двух моментов: концептуального различения между материальным и нематериальным в социологии повседневности и различий между двумя концепциями - пересобранной социологией повседневности В. Вахштайна и теорией множественных денег В. Зелизер.

\section{САОЖНОСТЬ СОВМЕСТИМОСТИ КОНЦЕПТУААЬНЫХ ОПТИК}

Рассмотрим подробнее эти два момента. Так как электронные деньги «находятся» на электронном счете и не ощущаются физически, они нематериальны. И есть теоретический соблазн вслед за Аатуром сказать, что электронные деньги есть актант, производящий различия, т. е. трансформирующий отношения в Сети (Аатур, 2020). По сути, это означает наделить нематериальную сущность способностью к социальному действию, так же как «действовали» «“имперская идентичность”, добавляющаяся к технологиям португальской колониальной экспансии, и математические уравнения, действующие на рынке наряду с товарами и торговцами» (Вахштайн, 2017: 40). В. Вахштайн говорит о том, что социологии гораздо проще расширить оптику, включив в нее вещи, т. е. стереть различия в способности совершать действия между людьми и нелюдьми, наделив последних возможностью не только пассивного нахождения во взаимодействии, но и активного действия, чем произвести «радикальный отказ от самого этого языка в пользу новой онтологии, уравнивающей в правах людей, вещи и идеи» (там же: 41). То, что предлагает акторно-сетевая теория, предполагает не просто расширение оптики, а «высвобождение» из оков социального объяснения еще и нематериальных сущностей: мир, в котором «не будет ни “материального”, ни “нематериального”, а только “действующие” или “недействующие” (там же: 41). И решение, наделяющее электронные деньги способностью действовать, лежит уже в области акторно-сетевой теории. Но, приняв его, как говорилось выше, необходимо принять также отказ от самого языка, т. е. от социологической аксиоматики в пользу действующих объектов.

Что касается теории В. Зелизер, то для ее концепции множественных денег как электронные, так и неэлектронные формы денег не имеют «материальности». Через 
ее оптику «видны» действующие люди, социальные отношения, в которых они состоят, и те смыслы, которые они вкладывают в деньги в зависимости от этих отношений и социальных контекстов. В каком-то смысле здесь можно провести аналогию с веберианской социологией, в которой также есть смыслы и действия, апеллирующие к ним. Применение оптики Зелизер к анализу электронных денег предполагает, что люди по смыслу отличают их от бумажных денег, поэтому осуществляют разное целевое распределение электронных и неэлектронных денег. В принципе, для нее, как мы отмечали, нет различия между капиталистическими и некапиталистическими (точнее было бы сказать, между символическими и экономическими) экономиками; но есть сферы - семья, благотворительность, наследство, маркировка статусных различий, которые уже и так нагружены смыслами, а деньги встраиваются в них, добавляя дополнительный смысловой элемент, и в зависимости от этого социальные отношения трансформируются и изменяются. В этом случае по большому счету не так важно, материальны или нематериальны сами деньги, главное, что нематериальны смыслы, вкладываемые в деньги. И неважно, обладают ли деньги физическим воплощением и как они конституируют взаимодействия.

То, что не представляет особой теоретической проблемы в концепции Зелизер, по большому счету все равно, на каком носителе расположены деньги: на телефоне, пластиковой карточке, бумажные ли они или в виде драгоценных камней в обществах символических экономик. Главное, что для людей деньги - множественный феномен, и они осуществляют их целевое распределение. Это приводит нас к мысли о сложности относительно концептуального различения материального и нематериального с точки зрения «пересобранной» В. Вахштайном социологии повседневности. Аля того чтобы признать за электронными деньгами способность действовать, нужно отказаться от самого языка в пользу множественных онтологий, предлагаемых акторно-сетевой теорией. Само разделение на электронные и неэлектронные деньги влечет за собой огромные последствия для материальной социологии повседневности. И тот факт, существует ли материальный носитель, сам по себе очень важен.

\section{ЗАКАЮЧЕНИЕ}

Феномен электронных денег остается не слишком основательно проработан в рамках социологической теории. На наш взгляд, качественная концептуальная оптика должна включать в себя как уровень смыслов, так и уровень повседневной жизни, над конструированием которой еще, видимо, предстоит работать. Как было продемонстрированно в данной работе, перспектива совместимости концепции множественных денег, позволяющей различить множественные смыслы относительно электронных и неэлектронных денег, и материальной социологии повседневности, предоставляющей теоретические ресурсы для описания использования различных форм денег в повседневной жизни, имеет как сложности, зависящие от принципиальных методологических расхождений этих концепций, так и теоретические возможности для дальнейших попыток концептуализации феномена электронных денег.

\section{ПРИМЕЧАНИЕ}

1 Чтобы избежать терминологических разногласий, отметим, что термины неэлектронные, бумажные и наличные деньги будут использоваться как синонимы, важен их материальный носитель, что отличает их от электронных денег. 


\section{СПИСОК АИТЕРАТУРЫ}

Аникаева, Е. А. (2008) Основные подходы к исследованию денег в социологии // Экономическая социология. Т. 9. № 1. С. 114-124.

Бурдье, П. (2019) Экономическая антропология : курс лекций в Коллеж де Франс (1992-1993) / пер. с фр. А. Кралечкина. М. : Издательский дом «Аело» РАНХиГС. 416 с.

Вахштайн, В. С. (2017) Пересборка повседневности: беспилотники, лифты и проект ПкМ-1// Могос. Т. 27. № 2. С. 1-48.

Вебер, М. (2016) Хозяйство и общество: очерки понимающей социологии : в 4 т. Т. 1. Социология / сост., общ. ред. и предисл. $\Lambda$. Г. Ионина. М. : Издательский дом Высшей школы экономики. 445 с.

Грановеттер, М. (2014) Экономическое действие и социальная структура: проблема укорененности // Классика новой экономической социологии / сост. В. В. Радаев, Г. Б. Юдин ; пер. с англ. и фр. ; под науч. ред. В. В. Радаева, Г. Б. Юдина. М. : Издательский дом Высшей школы экономики. 381 с. С. $345-379$.

Жэнгра, И. (2017) Социология науки / пер. с фр. С. А. Гашкова ; под ред. О. И. Кирчик. М. : Издательский дом Высшей школы экономики. 112 с.

Зелизер, В. (2004) Социальное значение денег. Аеньги на булавки, чеки, пособия по бедности и другие денежные единицы / пер. с англ. А. В. Смирнова, М. С. Аобряковой ; под. науч. ред. В. В. Радаева. М. : Аом интеллектуальной книги ; Издательский дом ГУ-ВШЭ. 248 с.

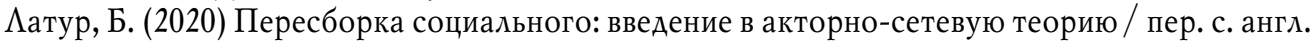
И. Полонской ; под ред. С. Гавриленко. 2-е изд. М. : Издательский дом Высшей школы экономики. 384 с.

Маркин, М. Е. (2015) Социальное значение электронных денег в современной России // Вестник общественного мнения. Аанные. Анализ. Аискуссии. № 3-4 (121). С. 121-129.

Попов, В. (2011) Мобильность и деньги: попытка конвергенции двух социологических теорий // Социологическое обозрение. Т. 10. № 1-2. С. 34-53.

Радаев, В. В. (2008) Экономические империалисты наступают! Что делать социологам? // Общественные науки и современность. №6. С. 116-123.

Халина, Н. В. (2013) Электронные деньги в России: восприятие населением современных способов платежей // Мониторинг общественного мнения: экономические и социальные перемены. № 2 (114). С. 122-130.

Ingham, G. (2000) "Babylonian madness": on the historical and sociological origins of money. In: Smithin, J. What is money? L. : Routledge. 276 p. P. 16-41.

Ingham, G. (2004) The Nature of Money. Cambridge : Polity Press. 254 p.

Smithin, J. (2000) What is money? L. : Routledge. 276 p.

Аата поступления: 05.04.2020 2.

\section{SOCIOLOGICAL CONCEPTUALIZATION OF ELECTRONIC MONEY: DIFFICULTIES AND PERSPECTIVES \\ E. S. MAKAROV \\ PLEKHANOV RUSSIAN UNIVERSITY OF ECONOMICS}

The article presents conceptualization of electronic money in different sociological analytical frameworks. Electronic money is considered as a multiple phenomenon embedded in social life both on the level of meanings and on the everyday level.

The research is based on the analysis of electronic money through the prism of two analytical frameworks - V. Zelizer's theory of multiple money and V. Vakhstain's material sociology of everyday life. The author makes conclusions about the compatibility options of these two concepts and about some fundamental differences between them.

Keywords: electronic money; sociology of money; economic sociology; multiple money; sociology of everyday life 
REFERENCES

Anikaeva, E. A. (2008) Osnovnye podhody k issledovaniju deneg v sociologii. Jekonomicheskaja sociologija. vol. 9, no. 1, pp. 114-124. (In Russ.).

Bourdieu, P. (2019) Jekonomicheskaja antropologija: kurs lekcij $v$ Kollezb de Frans (1992-1993) / transl. from French by D. Kralechkina. Moscow, Delo Publishing House at RANEPA. 416 p. (In Russ.).

Vakhshtayn, V. S. (2017) Peresborka povsednevnosti: bespilotniki, lifty i proekt PkM-1. Logos. vol. 27, no. 2, pp. 1-48. (In Russ.).

Weber, M. (2016) Hozjajstvo i obshbestvo: ocherki ponimajushbej sociologii: in 4 t. / comp., ed. and introductiction L. G. Ionin. Moscow, Publishing House at Higher School of Economics. Vol. 1. Sociologija. 445 p. (In Russ.).

Granovetter, M. (2014) Jekonomicheskoe dejstvie i social'naja struktura: problema ukorenennosti; comp. V. V. Radaev, G. B. Judin ; transl. from English and French; ed. by V. V. Radaev, G. B. Judin. Moscow, Publishing House at Higher School of Economics. 281 p. 345-379 pp. (In Russ.).

Gingras, Y. (2017) Sociologija nauki / transl. from French S. A. Gashkova; ed. by O. I. Kirchik. Moscow, Publishing House at Higher School of Economics. 112 p. (In Russ.).

Zelizer, V. (2004) Social'noe znachenie deneg. Den'gi na bulavki, cheki, posobija po bednosti $i$ drugie denezbnye edinicy / transl. from English by A. V. Smirnova, M. S. Dobrjakova; ed. by V. V. Radaev. Moscow, Intellectual Book House; Publishing House at SU-HSE. 284 p. (In Russ.).

Latour, B. (2020) Peresborka social'nogo: vvedenie v aktorno-setevuju teoriju / transl. from English I. Polonskoj; ed. by S. Gavrilenko. 2nd ed. Moscow, Publishing House at Higher School of Economics. 384 p. (In Russ.).

Markin, M. E. (2015) Social'noe znachenie jelektronnyh deneg v sovremennoj Rossii. Vestnik obshbestvennogo mnenija. Dannye. Analiz. Diskussii, no. 3-4 (121), pp. 121-129. (In Russ.).

Popov, V. (2011) Mobil'nost' i den'gi: popytka konvergencii dvuh sociologicheskih teorij. Sociologicheskoe obozrenie. vol. 10, no. 1-2, pp. 34-53. (In Russ.).

Radaev, V. V. (2008) Jekonomicheskie imperialisty nastupajut! Chto delat' sociologam? Obshbestvennye nauki i sovremennost', no. 6, pp. 116-123. (In Russ.).

Halina, N. V. (2013) Jelektronnye den'gi v Rossii: vosprijatie naseleniem sovremennyh sposobov platezhej. Monitoring obshbestvennogo mnenija: jekonomicheskie i social'nye peremeny, no. 2 (114), pp. 122-130. (In Russ.).

Ingham, G. (2000) "Babylonian madness": on the historical and sociological origins of money. In: Smithin, J. What is money? London, Routledge. 276 p. Pp. 16-41.

Ingham, G. (2004) The Nature of Money. Cambridge, Polity Press. 254 p.

Smithin, J. (2000) What is money? London, Routledge. 276 p.

Submission date: 05.04.2020.

Макаров Егор Сергеевич - студент факультета экономики и права кафедры политологии и социологии Российского экономического университета имени Г. В. Плеханова. Адрес: 117997, Россия, г. Москва, Стремянный пер., 28, корп. 1. Тел.: +7 (495) 958-23-27. Эл. адрес: eg.makaraz@mail.ru. Научный руководитель - канд. социол. наук А. А. Тихомиров.

Makarov Egor Sergeyevich, Student, Faculty of Economics and Law, Department of Political Science and Sociology, Plekhanov Russian University of Economics. Postal address: 28, Bldg. 1, Stremyanny Lane, Moscow, Russian Federation, 117997. Tel.: +7 (495) 958-23-27. E-mail: eg.makaraz@ mail.ru. Scientific Advisor - D. A. Tikhomirov, Candidate of Sociology. 